\title{
Proposed New Schemes to Reduce PAPR for STBC MIMO FBMC systems
}

\author{
Imad A Shaheen \\ Electronics and communication Dep. \\ Ain Shams University \\ Cairo-Egypt \\ Fatma Newagy \\ Electronics and communication Dep. \\ Ain Shams University \\ Cairo-Egypt
}

\author{
Abdelhalim Zekry \\ Electronics and Communication Dep. \\ Ain Shams University \\ Cairo-Egypt \\ Reem Ibrahim \\ Embedded System Design \\ Electronics Factory \\ Cairo-Egypt
}

\begin{abstract}
Filter bank multicarrier (FBMC) system support better spectral efficiency and high data rate compared to OFDM system. However, the capacity of FBMC system can be increased significantly by occupying Multiple Input and Multiple Output MIMO system. The combination of MIMO and FBMC system may be used for next communication system 5G to support high spectral efficiency. The major disadvantage of FBMC MIMO system are high peak to average power ratio (PAPR) which reduced the performance of the FBMC system .There are many reduction techniques have been used to reduce PAPR. However, The nonlinear companding technique and Precoding system used widely to reduced peak to average power ratio (PAPR) for Multicarrier Modulation(MCM) System. In this paper, we Proposed new schemes based on the combination of Walsh-Hadamard Transform (WHT) Precoding with the companding technique based on the A-law and Mu-law technique to reduce PAPR for MIMO FBMC system with using Space Frequency Block Coding (STBC). Moreover, the Precoding Technique used in the frequency domain and nonlinear companding technique in the time domain. However, simulation results show that the combination of WHT precoding with A-law companding can achieve a better PAPR reduction and bit error rate(BER) performance compared to the combination of the WHT precoding with $\mathrm{Mu}$ companding technique.
\end{abstract}

\section{Keywords}

multiple-input multiple-output (MIMO), FBMC/OQAM, peak-to-average power ratio (PAPR), A-Law companding, Mu-law, STBC, WHT precoding.

\section{INTRODUCTION}

In the multicarrier transmission, the subcarriers are independent of each other in time domain such composite signal has a large dynamic range as subcarriers may align to produce constructive or destructive superposition constructive superposition will result in the signal will high values of envelope peaks whereas destructive superposition may fade signal completely such large variation in signal power is measured in peak to average power ratio. Filter Bank Multicarrier with Offset Quadrature Amplitude Modulation System (FBMC/OQAM) as one of the many new waveforms is proposed for the next wireless communication generation $5 \mathrm{G}$. The FBMC system is a multicarrier modulation scheme with relaxed orthogonally, increased frequency efficiency, improved shape and low out-of-band interference inherent in FBMC/OQAM techniques[1].From the past decades there are many schemes proposed to reduced PAPR for FBMC system, and still, many researchers are focusing on emerging PAPR reduction schemes with more effective results and fewer implementations complexity. The next generation of wireless communication systems (5G) supports many advantages like low latency wireless communication system, high data rate, low interference, high spectral efficiency. all these advantages cannot support with OFDM, due to that new waveforms are designed such as FBMC/OQAM which used filter prototype for pulses shaping to reduced interference in systems. However, Multiple-input multiple-output (MIMO) systems use multiple antennas between the transmitter and the receiver to speed throughput and to increase the coverage and reliability of wireless communications [2-3]. Multiple inputs multiple outputs (MIMO) with FBMC/OQAM system is an emerging technology for high-speed data multicarrier transmission in future wireless communication network systems[4-5]. Whenever the phases and frequencies of these carriers match coherently, instantaneous power outputs may increase greatly and become higher than the mean power of the high power amplifier (HPA) resulting in large PAPR. Many of research has been done for solving the problem of PAPR such as clipping, tone reservation, nonlinear transformations, coding, selecting mapping (SLM) and partial transmit sequence(PTS)[5-6-7].However, the computational complexity is still remaining unsolved totally.

In this paper, we propose new schemes consist of a combination of WHT Precoding with Nonlinear companding technique based on A law and MU law which applied to reduce the PAPR for MIMO FBMC/OQAM system with space frequency block coding (STBC) with a low implementation complexity.However, in MIMO scheme, we used two transmission antenna and one receive antenna. The organization of this paper is as follows: in section II, FBMC/OQAM modulation with using square root raised cosine filter (SRRC) for prototype filter then introduced MIMO in FBMC.OQAM system in section III, introduced the PAPR in MIMO system, then in section IV, The WalshHadamard Transform Precoding Techniques is explained ,in section V , Companding scheme is explained with two sorts which are A-law and $\mathrm{Mu}$ - law companding, then in section VI, Proposed STBC Alamouti MIMO FBMC with Precoding and nonlinear companding system is explain . in section VII 
the simulation results are presented. Last section VIII concludes the paper.

\section{FBMC/OQAM SYSTEM MODEL}

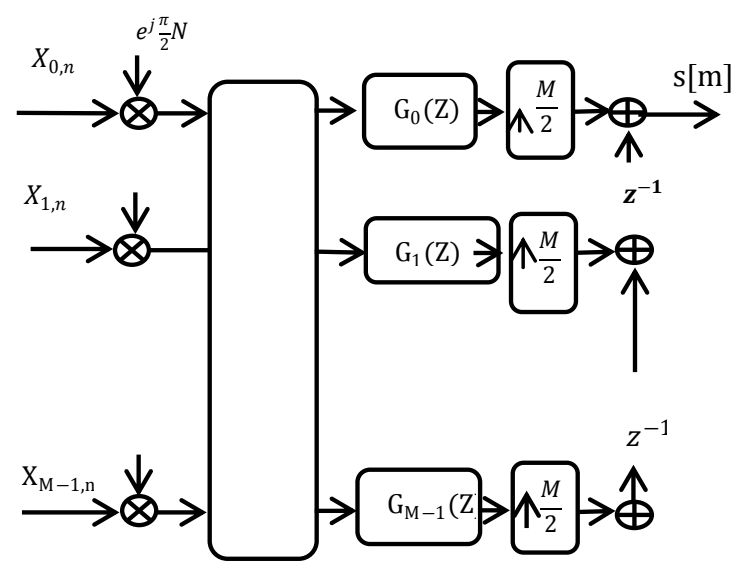

Fig 1: The FBMC/OQAM Transmitter

Figure 1 shows the FBMC/OQAM Transmitter with using nonlinear companding. the transmitter is consisted from the OQAM preprocessing, IFFT follows by PolyPhase filter bank and companding technique consequently the FBMC/OQAM system used to transmits the OQAM instead of transmitting QAM data.

Let us denote $\mathrm{x}_{k, n}$ as the transmitted symbols which is either reallor the imaginary component of input symbol . the baseband transmitting signal can be written as [2-3-4]

$s_{n}=\sum_{k=0}^{M-1} \quad \sum_{n=-\infty}^{+\infty} X_{k, n} T e^{j \frac{2 \pi k}{M}\left(m-\frac{D}{2}\right)} e^{j \emptyset_{k, n}}$

Where $T=g[m-n M / 2]$ means prototype filter using SRRC [8], with filter length expressed as $L g=K M$, where $K$ is mean prototype filter frequency response and $M$ is the total number of subcarriers and $D / 2$ is a delay time

Where $\mathrm{D}=\mathrm{L}_{\mathrm{g}}-1=\mathrm{KM}-1$

The term $\emptyset_{\mathrm{k}, \mathrm{n}}$ is used for the phase shift along the time and frequency axes for transmitted symbols and can be given by

$\emptyset_{\mathrm{k}, \mathrm{n}}=\frac{\pi}{2}(\mathrm{n}+\mathrm{k})-\pi \mathrm{kn}$

The expression of the discrete-time baseband signal can be expressed as:

$\mathrm{s}[\mathrm{m}]=\sum_{\mathrm{k}=0}^{\mathrm{N}-1} \quad \sum_{\mathrm{n}=-\infty}^{+\infty} \mathrm{X}_{\mathrm{k}, \mathrm{n}} \mathrm{g}_{\mathrm{k}, \mathrm{n}}[\mathrm{n}]$

Where $g_{k, n}[m]$ is defined by

$g_{k, n}[m]=g[m-N / 2] e^{j \frac{2 \pi k}{M}\left(m-\frac{D}{2}\right)} e^{j \emptyset_{k, n}}$

The received signal can be expressed as

$\mathrm{r}_{\mathrm{k}, \mathrm{n}}=\sum_{\mathrm{m}=-\infty}^{+\infty} \mathrm{s}[\mathrm{m}] \mathrm{g}_{\mathrm{k}, \mathrm{n}}^{*}[\mathrm{~m}]$

$\mathrm{r}_{\mathrm{k}, \mathrm{n}}=\mathrm{X}_{\mathrm{k} . \mathrm{n}}+\sum_{\mathrm{k}^{\prime}, \mathrm{n}^{\prime} \neq \mathrm{k} . \mathrm{n}} \mathrm{X}_{\mathrm{k}^{\prime}, \mathrm{n}^{\prime}} \sum_{\mathrm{n}=-\infty}^{+\infty} \mathrm{X}_{\mathrm{k}^{\prime}, \mathrm{n}^{\prime}}[\mathrm{n}] \mathrm{g}_{\mathrm{k}^{\prime}, \mathrm{n}^{\prime}}^{*}[\mathrm{n}]$

Where the prototype filter is designed with satisfied the orthogonal condition.
$\mathrm{R}\left\{\sum_{\mathrm{n}=-\infty}^{+\infty} \mathrm{g}_{\mathrm{k}^{\prime} \mathrm{n}^{\prime},}[\mathrm{m}] \mathrm{g}_{\mathrm{k}, \mathrm{n}}^{*}[\mathrm{~m}]\right\}=\delta_{\mathrm{k}, \mathrm{k}^{\prime}} \delta_{\mathrm{n}, \mathrm{n}^{\prime}}$

Then the receive signal can written as

$r_{k, n}=a_{k . n}+\sum_{k^{\prime}, n^{\prime} \neq k . n} a_{k^{\prime}, n^{\prime}} \sum_{m=-\infty}^{+\infty} a_{k^{\prime}, n^{\prime}}[m] g_{k^{\prime}, n^{\prime}}^{*}[m]$

$r_{k, n}=a_{k . n}+I_{k . n}=a_{k . n}+j u_{k . n}$

$\mathrm{I}_{\mathrm{k} . \mathrm{n}}=\sum_{\mathrm{k}^{\prime}, \mathrm{n}^{\prime} \neq \mathrm{k} . \mathrm{n}} \mathrm{d}_{\mathrm{k}^{\prime}, \mathrm{n}^{\prime}} \sum_{\mathrm{n}=-\infty}^{+\infty} \mathrm{d}_{\mathrm{k}^{\prime}, \mathrm{n}^{\prime}}[\mathrm{n}] \mathrm{g}_{\mathrm{k}^{\prime}, \mathrm{n}^{\prime}}^{*}[\mathrm{n}]$

Where is $I_{k . n}$ is represents the inherent intersymbol interference of an FBMC.OQAM

\subsection{FBMC/OQAM With MIMO SYSTEM}

In this section, we introduced the used of the Space-Time Block Coding (STBC) Alamouti with FBMC/OQAM[9]. Let's we have transmitter antenna $\mathrm{j}$ and a received antenna $\mathrm{i}$, the transmitted real data at time $\mathrm{n}$ and at frequency $\mathrm{k}$ expressed as $\mathrm{X}_{\mathrm{k}, \mathrm{n}}^{(\mathrm{i})}$ then the received signal $\mathrm{r}_{\mathrm{k}, \mathrm{n}}^{(\mathrm{i})}$ express as

$$
r_{k, n}^{(i)}=h_{k, n}^{(i j)}\left(X_{k, n}^{(j)}+j u_{k, n}^{(j)}\right)+\gamma_{k, n}^{(i)}
$$

Where $h_{k, n}^{(i j)}$ is the channel coefficient from the transmit antenna $\mathrm{j}$ to the receive antenna $\mathrm{i}$ at frequency $\mathrm{k}$ and time instant $\mathrm{n}, \gamma_{\mathrm{k}, \mathrm{n}}^{(\mathrm{it})}$ is the noise produced by transmitter antenna, $u_{k, n}^{(j)}$ is the interference term, however, The MIMO system used transmitter antenna $\mathrm{N}_{\mathrm{t}}$ to transmit data and used received antenna $\mathrm{N}_{\mathrm{r}}$ to receive signals[10-11-12-13]. The STBC MIMO FBMC receive signal at the jth receive antenna and at a given time-frequency position $(k, n)$ is expressed by

$r_{k, n}^{(j)}=\sum_{i=1}^{N_{t}} h_{k, n}^{(i j)}\left(X_{k, n}^{(i)}+j u_{k, n}^{(i)}\right)+\gamma_{k, n}^{(j)}$

Finally the matrix

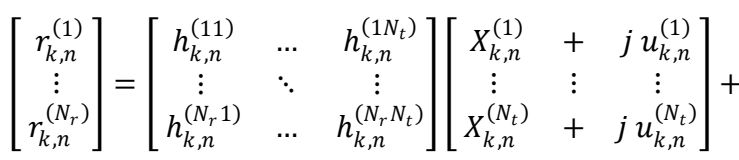

$\left[\begin{array}{c}\gamma_{k, n}^{(1)} \\ \vdots \\ \gamma_{k, n}^{\left(N_{r}\right)}\end{array}\right]$

$r_{k, n}=H_{k, n}\left(X_{k, n}+j u_{k, n}\right)+\gamma_{k, n}$

Where is $H_{k, n}$ is an $\left(N_{r} \times N_{t}\right)$

\subsection{PAPR theORY in MIMO System}

The peak to average power ratio of a transmitted signal is the main disadvantage in multicarrier modulation such as Multiple input Multiple output (MIMO) FBMC. PAPR can be expressed as the maximum power of a sample in a transmit FBMC symbol to its average power[14].

$\mathrm{PAPR}=10 \log _{10}\left\{\frac{\mathrm{P}_{\text {peak }}}{\mathrm{P}_{\text {avg }}}\right\}$

The PAPR of FBMC/OQAM transmitting signal can be written as

$\operatorname{PAPR}(\mathrm{s}[\mathrm{m}])=10 \log _{10} \frac{\operatorname{Max}\left\{|\mathrm{s}[\mathrm{m}]|^{2}\right\}}{\mathrm{E}\left\{|\mathrm{s}[\mathrm{m}]|^{2}\right\}} \mathrm{dB}$ 
Where $\mathrm{E}\{$.$\} express the expectation operation, we consider$ the MIMO-FBMC systems with $\mathrm{j}$ transmit antennas that use $\mathrm{i}$ subcarriers. Then the PAPR is actually the maximum PAPR value of all the transmit antennas[14-15].

$P A P R_{i}=\max \left(P A P R_{1}, P A P R_{2}, \ldots \ldots . . P A P R_{M}\right)$

Where $P A P R_{j}$ represents the peak to average power ratio of $\mathrm{j}^{\text {th }}$ transmit antenna and it given by as

$P A P R_{j}=P A P R\left\{s_{j}[n]\right\}=\max \frac{\left\{\left|s_{j}[m]\right|^{2}\right\}}{E\left\{\left|s_{j}[m]\right|^{2}\right\}}$

Then, the complementary cumulative distribution function (CCDF) of the PAPR of an FBMC signal for all $j$ transmit antennas exceeds a predefined threshold $\mathrm{PAPR}_{0}$ is given a given

$$
\begin{aligned}
C C D F & =P\left(P A P R\left(s_{i}[n]\right)>P A P R_{0}\right) \\
& =1-\left(1-e^{-P A P R_{0}}\right)^{M N}
\end{aligned}
$$

\section{THE WALSH HADAMARD TRANSFORM (WHT) PRECODING TECHNIQUES}

The primary rule to utilize the precoding method in the multicarrier system to reduce the PAPR and the interference of multiple users. The primarily favorable circumstances of precoding are: no transmission capacity extension, not required more power, no information misfortune, not required to send side information to the receiver and provide good BER performance[17].

The strategy of Hadamard Transform is utilized as a part of this paper which in view of the relationship between connection property of information flag and PAPR probability. However, the main concept of the WHT is to reduce the autocorrelation of the input signal. The WHT is a non-sinusoidal, orthogonal transform and it can easy implemented like FFT due to that it does not increase system complexity[18]. The function of WHT can be written as follows:

$\mathrm{H}_{1}=[1]$

$\mathrm{H}_{2}=\frac{1}{\sqrt{2}}\left[\begin{array}{cc}1 & 1 \\ 1 & -1\end{array}\right]$

$\mathrm{H}_{2 \mathrm{~N}}=\frac{1}{\sqrt{2 \mathrm{~N}}}\left[\begin{array}{cc}\mathrm{H}_{\mathrm{N}} & \mathrm{H}_{\mathrm{N}} \\ \mathrm{H}_{\mathrm{N}} & -\mathrm{H}_{\mathrm{N}}\end{array}\right]$

The WHT Precoding for a signal $\mathrm{S}_{\mathrm{i}}$ of length $\mathrm{N}$ is applied at the transmitter are expressed as

$\mathrm{y}_{\mathrm{n}}=\frac{1}{\mathrm{~N}} \sum_{\mathrm{i}=0}^{\mathrm{N}-1} \mathrm{~S}_{\mathrm{i}} \mathrm{WAL}(\mathrm{n}, \mathrm{i})$

and at the receiver, we applied the inverse version of the WHT which expressed as

$\mathrm{s}_{\mathrm{i}}=\frac{1}{\mathrm{~N}} \sum_{\mathrm{i}=0}^{\mathrm{N}-1} \mathrm{y}_{\mathrm{n}} \mathrm{WAL}(\mathrm{n}, \mathrm{i})$

Where $\mathrm{i}=0,1, \ldots \ldots, \mathrm{N}-1$ and WAL (n,i) are Walsh functions

\section{COMPANDING TECHNIQUE}

Nonlinear companding scheme used in the multicarrier system because it provides great PAPR reduction, best BER performance, and less complexity[19].

\subsection{A law Companding Technique}

Figure 2 shows the A-law compressor characteristics with a different value of A ratio which used to control the amount of companding in the FBMC signal. From the figure we can observe that when the compression ratio parameter ' An' increases the results more compression of the signal. However when we fixed the value of companding ratio equal to one then we observe that no compression of the signal. The companding function applied to the end of the transmitter side is express by[19-20]

$F(s[m])=\operatorname{sgn}(s[m])\left\{\begin{array}{cl}\frac{A|s[m]|}{1+\ln (\mathcal{R}(A)} & ,|s[m]|<\frac{|s[m]|_{\max }}{A} \\ \frac{1+\ln (A|s[m]|}{1+\ln [(A)} & ,|s[m]| \geq \frac{|s[m]|_{\max }}{A}\end{array}\right.$

Where A is used to control companding function The inverse companding at the receiver is given by

$$
\begin{aligned}
& F^{-1}(r) \\
& =\operatorname{sgn}(r) \begin{cases}\frac{|r|(1+\ln (A))}{A} & ,|r|<\frac{|r|_{\max }}{1+\ln ((A)} \\
\frac{\exp (|r|(1+\ln (A))-1)}{A}, & |r| \geq \frac{|r|_{\max }}{1+\ln (A)}\end{cases}
\end{aligned}
$$

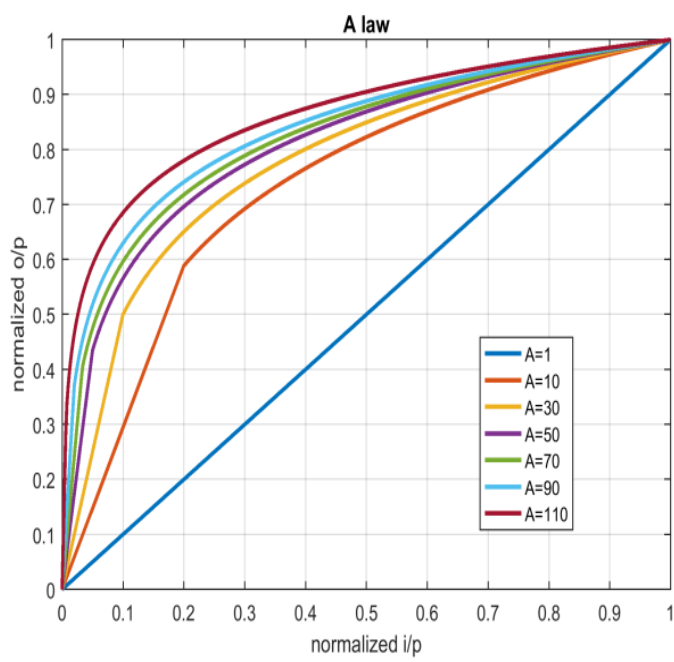

Fig 2 : A law compressor characteristics

\subsection{Mu law Companding Technique}

Figure 3 show the Mu-law compressor characteristics with different value of $\mathrm{Mu}$ ratio which used for control the amount of companding in the FBMC signal so from figure we can observe that when the MU ratio increases the results more compression, when $\mathrm{Mu}=1$, we observe that no compression 


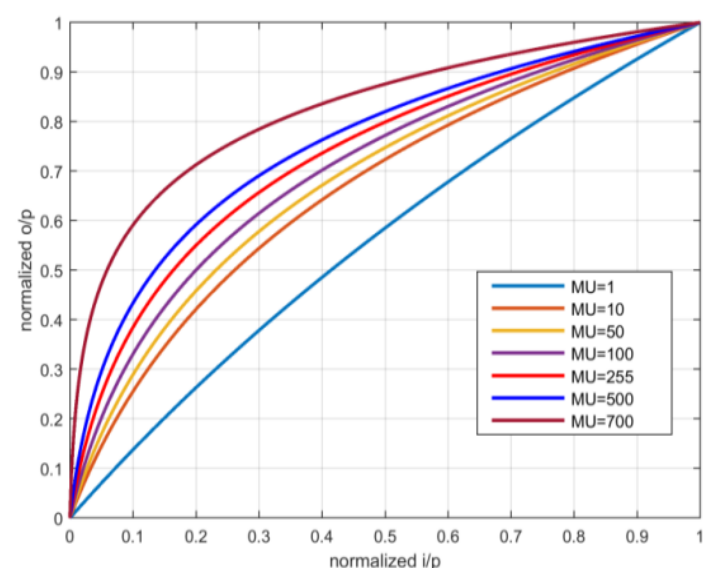

Fig 3 : Mu-law compressor characteristics

The companding function applied to the end of the transmitter side is express by [21-22]

$F(s[m])=\operatorname{sgn}(s[m]) \frac{\ln [(1+M u|s[m]|}{\ln (1+M u)}$,

(28) Where $\mathrm{Mu}$ parameter used to control the companding level applied to the signal. The inverse companding at the receiver is given by

$F^{-1}(r)=\operatorname{sgn}(r)\left(\frac{1}{M u}\right)\left((1+M u)^{|r|}-1\right)$,

\section{PROPOSED STBC ALAMOUTI MIMO FBMC WITH PRECODING AND COMPANDING SYSTEM MODEL}

For reduced the PAPR of Alamouti MIMO FBMC/OQAM system with using precoding scheme and companding technique with using $\mathrm{M}$ transmit antennas that used $\mathrm{N}$ subcarriers. The precoding transform is applied in the frequency domain and the companding transform is applied

to time domain. The system block of the proposed scheme is shown in figure 5 . The signal processing step is below

Step 1: The input streams are passed to the symbol subcarrier mapping then it passed to Walsh-Hadamard transform (WHT) precoding technique.
$\mathrm{Y}[\mathrm{m}]=\mathrm{H} \mathrm{S}[\mathrm{m}]$

Step 2: Then it passed through the preprocessing OQAM modulation then it will pass through the serial to parallel converter.

Step3: The modulated data fed to the STBC which generated two sequence S1, S2, as a proceed Antenna TX1, Antenna TX2 for transmitter respectively and Each sub-block contains part of input data. the sequence for the 1st antenna is express as

$\mathrm{S}_{1}=\left[\mathrm{s}_{1},-\mathrm{s}_{2}^{*}, \mathrm{~s}_{3},-\mathrm{s}_{4}^{*} \ldots \ldots \ldots \mathrm{s}_{\mathrm{N}-1}, \mathrm{~s}_{\mathrm{N}}^{*}\right]$

The sequence for the 2nd antenna is express as $\mathrm{s}_{2}=\left[\mathrm{s}_{2}, \mathrm{~s}_{1}^{*}, \mathrm{~s}_{4},-\mathrm{s}_{3}^{*} \ldots \ldots \ldots \mathrm{s}_{\mathrm{N}}, \mathrm{s}_{\mathrm{N}-1}^{*}\right]$

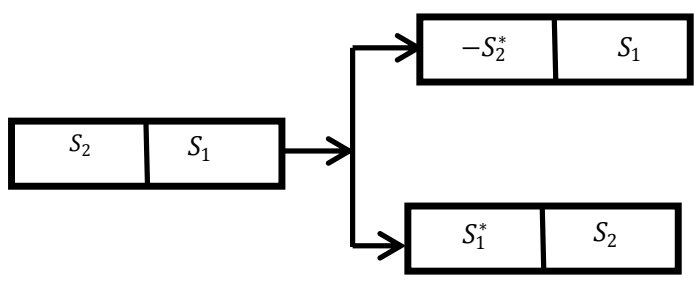

Fig 4: Signal transmit mode

From eq. (31) and eq. (32) means that in the 1st time slots signal $s_{1}$ and $s_{2}$ are transmitted from the 1 st and 2 nd antennas respectively, in 2nd-time slot signal $-s_{2}^{*}$, and $s_{1}^{*}$ are transmitted from the s two antennas and so on as shown in figure 4.

Step 4: Then both of this sequence is passed through IFFT

$s_{n}=\operatorname{IFFT}\left\{S_{n}\right\}$ for $n=0,1, \ldots \ldots \ldots, M-1$

Step 5: Output of the IFFT passed to the synthesis filterbank

Step 6: The output from SFB passed through the parallel to serial converter before it passed through the companding technique block which used to reduce the PAPR.

At the receiver side the inverse operation is done for each stage, also it is not required to send side information to the receiver, which reduces the system throughput. 


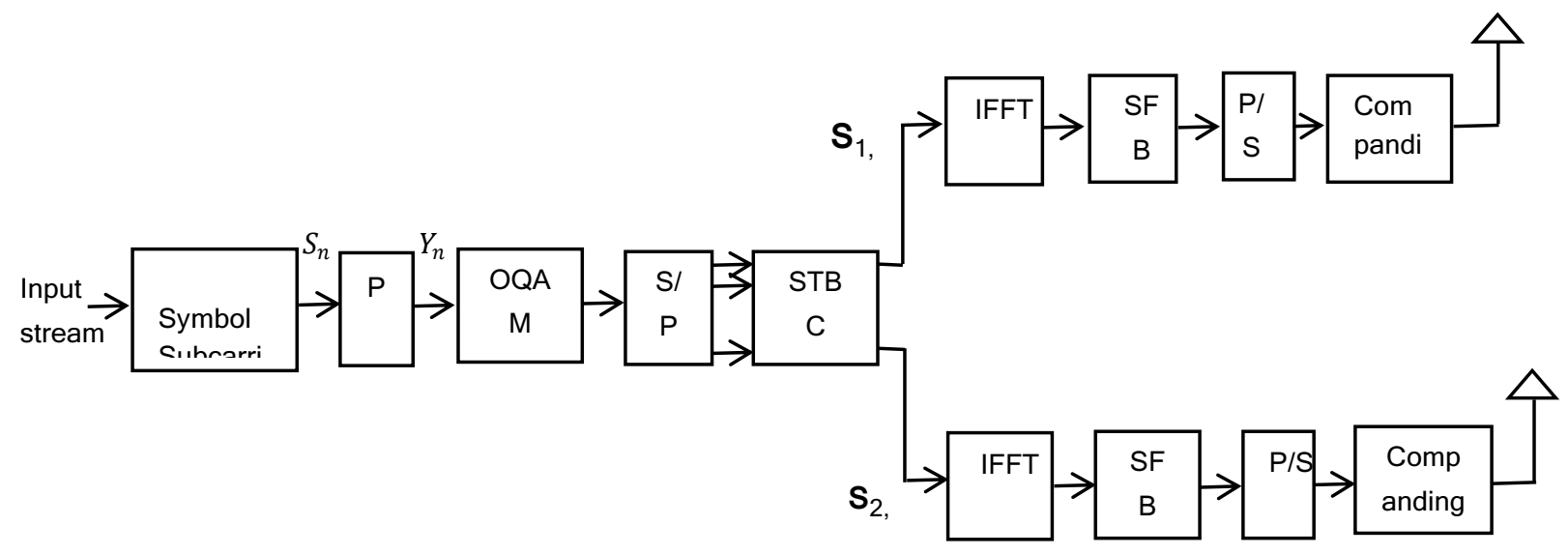

Fig 5 : Proposed STBC Alamouti MIMO FBMC Transceiver with Precoding and Companding

\section{SIMULATION RESULTS}

In this section, the simulation results are obtained for proposed transceiver of STBC MIMO FBMC/OQAM systems with using two transmitter antenna and one receive antenna. table I show the parameter used in our simulation

Table I Parameter used in the simulationFor MIMO FBMC system

\begin{tabular}{|l|l|l|}
\hline No. & Parameters & Values \\
\hline 1 & Number of repetitions & 1024 \\
\hline 2 & Number of subcarriers & 512 \\
\hline 3 & SNR range & $0-25$ \\
\hline 4 & MIMO Scheme & STBC \\
\hline 5 & Modulation Technique & OQAM \\
\hline 6 & Prototype filter & SRRC \\
\hline 7 & Roll-off factor & 0.5 \\
\hline 8 & over sampling factor & 8 \\
\hline 9 & Precoding scheme & WHT \\
\hline 10 & Companding technique & $\begin{array}{l}\text { A-law and } \\
\text { Mu-law }\end{array}$ \\
\hline
\end{tabular}

Fig.6. Shows the complementary cumulative distribution function (CCDF) with using Mu-law companding scheme with applied different value of $\mathrm{Mu}$ companding ratio which chose to be $\{5,10,100,255,500\}$. However, From figure 6 and table II, we can observe that when the values of Mu parameter increase then the CCDF of PAPR improves means there is an inverse relationship between $\mathrm{Mu}$ parameter and CCDF. Therefore, the best one improvement for PAPR at Mu ratio set to be 500 .

Table II PAPR for different MU-companding ratio For MIMO FBMC system

\begin{tabular}{|r|l|l|l|l|l|l|}
\hline $\begin{array}{r}\text { Mu } \\
\text { ratio }\end{array}$ & $\begin{array}{l}\text { Without } \\
\mathrm{Mu}\end{array}$ & 10 & 50 & 100 & 255 & 500 \\
\hline PAPR & 12.31 & 6.54 & 5.591 & 4.594 & 3.886 & 3.796 \\
\hline
\end{tabular}

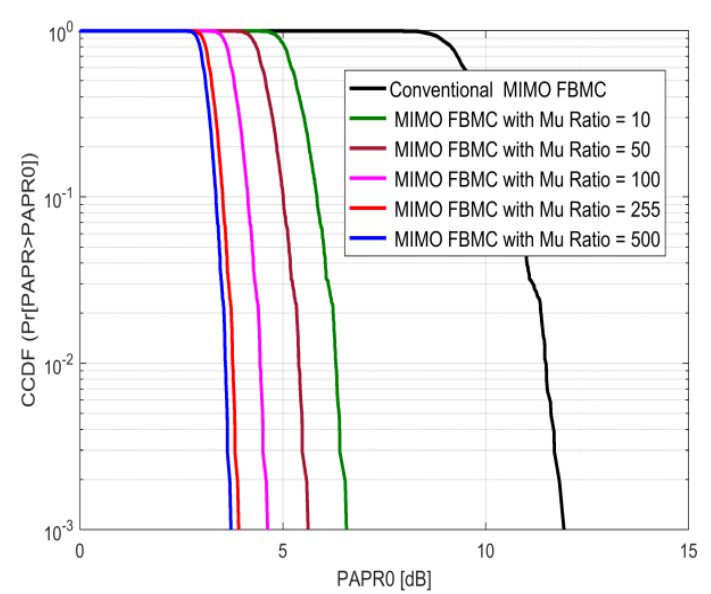

Fig 6: CCDF of PAPR MIMO FBMC system with Mu-law companding for various Mu Parameters.

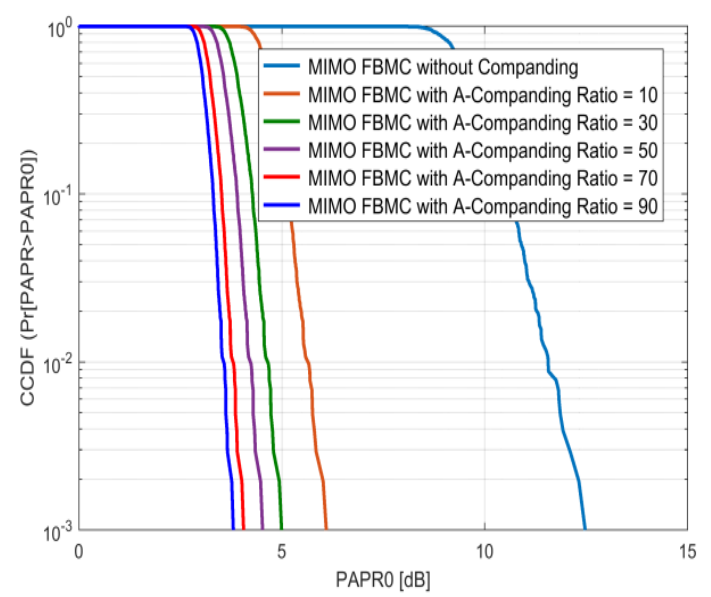

Fig 7: CCDF of PAPR MIMO FBMC system with A Companding for various A parameter.

Fig.7. Shows the complementary cumulative distribution function (CCDF) with using A-Law companding scheme with applied different value of A companding ratio which chose to be $\{10,30,50,70,90\}$. However, From figure 7 and table III, 
we can observe that when the values of A parameter increase then the CCDF of PAPR improves means there is an inverse relationship between A parameter and CCDF. Therefore, the best one improvement for PAPR at A ratio set to be 90 .

Table III PAPR for different A Companding ratio for MIMO FBMC system

\begin{tabular}{|l|l|c|l|l|l|l|}
\hline $\begin{array}{l}\text { A- } \\
\text { ratio }\end{array}$ & $\begin{array}{l}\text { Withou } \\
\mathrm{t} \\
\text { Comp. }\end{array}$ & 10 & 30 & 50 & 70 & 90 \\
\hline $\begin{array}{l}\text { PAP } \\
\mathrm{R}\end{array}$ & 12.31 & $\begin{array}{c}5.83 \\
0\end{array}$ & $\begin{array}{l}4.33 \\
6\end{array}$ & $\begin{array}{l}3.89 \\
2\end{array}$ & $\begin{array}{l}3.75 \\
1\end{array}$ & $\begin{array}{l}3.69 \\
3\end{array}$ \\
\hline
\end{tabular}

Figure 9 Shows the complementary cumulative distribution function with using different schemes. From the fig 8 and fig 9, we can observe that when we used combination of $\mathrm{A}$ companding with WHT Precoding is used with fixed A- ratio to 90 , the PAPR is reduced about $9.687 \mathrm{~dB}$ and when Mu-law companding with WHT Precoding is used with Mu ratio fixed to 500 , the PAPR is reduced about $9.227 \mathrm{~dB}$ Whereas Acompanding and Mu companding reduced PAPR about 8.617 $\mathrm{dB}, 8.514 \mathrm{~dB}$ respectively . therefore the proposed schemes consist from WHT precoding technique with A- law companding given better reduction than others.

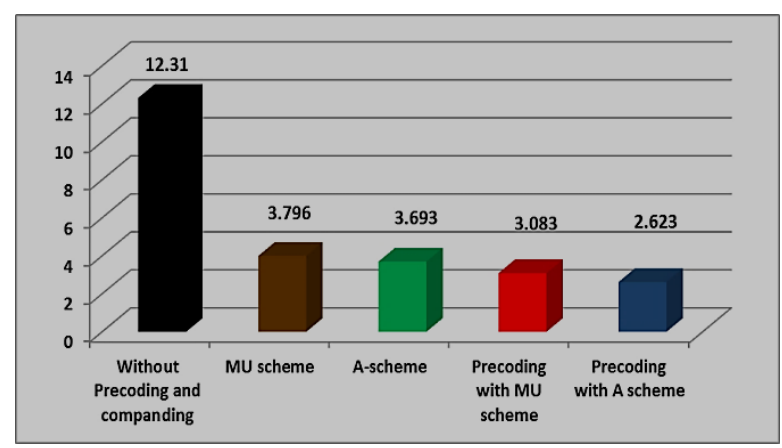

Fig 8: Comparative analysis of PAPR(dB) Reduction in MIMO FBMC system shows reduction value

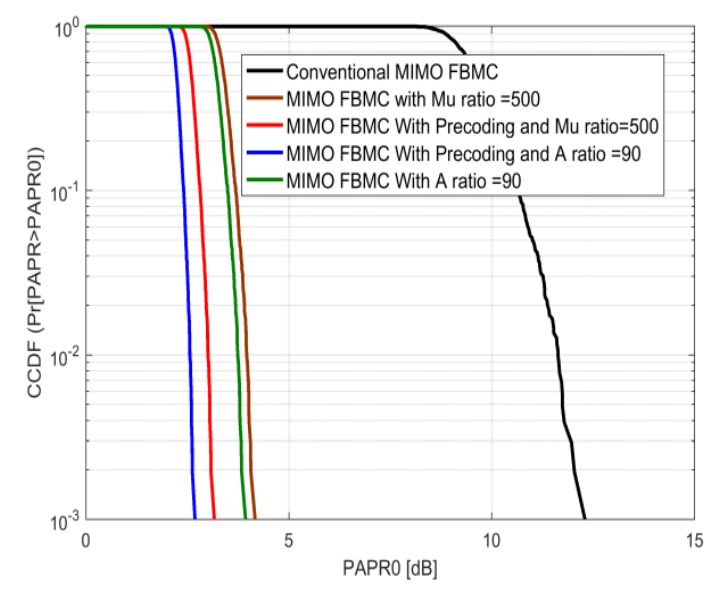

Fig 9: CCDF of PAPR MIMO FBMC system with different schemes

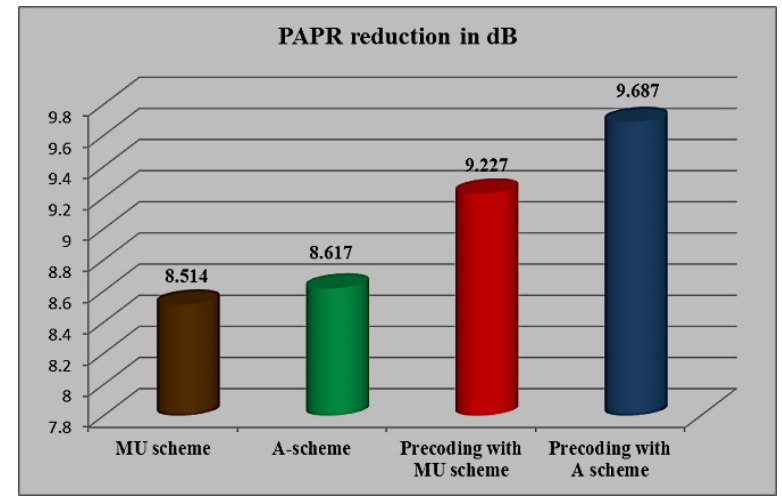

Fig 10: Reduction level for various technique in MIMO FBMC system

Figure 10 shows the reduction level for the original MIMO FBMC system with using different schemes. It shows that the PAPR is reduced to a great extent when precoding and Alaw companding is mixed together it can reduce the PAPR by $9.686 \mathrm{~dB}$.

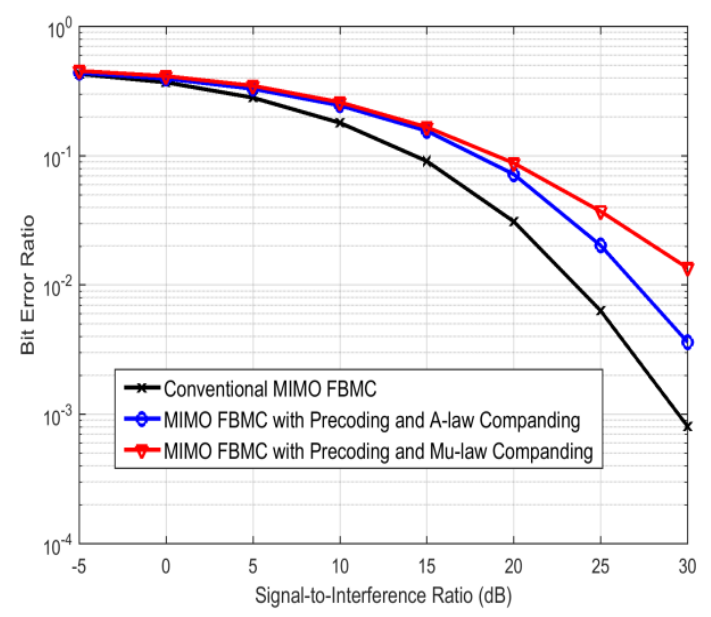

Fig 11: BER versus SNR MIMO FBMC system with Hybrid Precoding with Companding

Figure 11 shows the competitive analysis of Bit error rate in MIMO FBMC system out of the two reduction schemes based on the precoding with MU law companding and precoding with A-law companding schemes which compared to the original FBMC without any reduction schemes. However, we can observe that the best BER is produced by using combination of the preceding with A-law companding law

\section{CONCLUSION}

MIMO FBMC system is found to be used for next wireless communication $5 \mathrm{G}$ system .it is satisfied various advantages as support better spectrum efficiency, high diversity gain and system capacity. However, the most disadvantaged issue are high PAPR especially when signal access nonlinear devices, it may require wide dynamic range, or may be cause nonlinear distortion due to that it degrades the overall performance; this paper presents an STBC Alamouti MIMO FBMC system with two antenna transmitter and one antenna receiver. However, The STBC Alamouti MIMO FBMC system are implemented with applied combination of two technique to reduced PAPR First technique are WHT Precoding and second technique are 
nonlinear companding technique based on the Mu-law and Alaw companding which applied separately to the system to compare the performance between them . from our simulation we can say that all these techniques are able to provide great reduction in PAPR but the combination based on the WHT Precoding with A-law companding schemes provide better performance to minimizes the PAPR as well as provides good BER performance. We can say that the STBC Alamouti MIMO FBMC system for next wireless communication is better to build with the combination of the Walsh-Hadamard transform (WHT) with A-law companding technique.

\section{REFERENCES}

[1] Arun Kumar and Manisha Gupta. Article: Keys Technology and Problem in Deployment of 5G Mobile Communication Systems. Communications on Applied Electronics 1(3):4-7, February 2015. Published by Foundation of Computer Science, New York, USA.

[2] M. Bellanger, "Physical layer for future broadband radio systems," in 2010 IEEE Radio and Wireless Symposium (RWS), Jan. 2010, pp. 436-439

[3] B. Farhang-Boroujeny, "OFDM Versus Filter Bank Multicarrier,” IEEE Signal Process. Magaz., vol. 28, no. 3, pp. 92-116, May 2011.

[4] D. S. Waldhauser and J. A. Nossek, "Multicarrier systems and filter banks," Advances in Radio Science, vol. 4, pp. 165-169, 2006.

[5] Ku, Sheng-Ju. "A Low-Complexity PTS Scheme for PAPR Reduction in SFBC MIMO OFDM Systems", 2014 IEEE 80th Vehicular Technology Conference (VTC2014-Fall),2014.

[6] Tiwari, Harshita, Rakesh Roshan, and Rajat Kumar Singh. "PAPR reduction in MIMO- OFDM using combined methodology of selected mapping (SLM) and partial transmit sequence (PTS)", 2014 9th International Conference on Industrial and Information Systems (ICIIS), 2014

[7] C. Jose and S. M. Deepa, "Peak to Average Power Ratio Reduction and Inter Symbol Interference Cancellation of FBMC-OQAM signals," International Journal of Engineering Research \& Technology, vol. 03, no. 03, pp. 1890 - 1894, Mar. 2014.

[8] Chia-Yu Yao and Chiang-Ju Chien, "Design of a squareroot-raised-cosine FIR filter by a recursive method," 2005 IEEE International Symposium on Circuits and Systems, 2005, pp. 512-515 Vol

[9] Jaya Dagur and Savita Rangi. BER based Performance Analysis of $4 \times 2$ MIMO Diversity with Encoder and Interleaver for BPSK, QPSK and QAM. Communications on Applied Electronics 5(4):31-36, June 2016.

[10] M. Caus and A. I. Perez-Neira, "Transmitter-Receiver Designs for Highly Frequency Selective Channels in MIMO FBMC Systems," in IEEE Transactions on Signal Processing, vol. 60, no. 12, pp. 6519-6532, Dec. 2012.

[11] Yun Li, , Mingyu Gao, and Zhiqiang Yi. "A cooperative and alternate PTS scheme for PAPR reduction in STBC MIMO-OFDM system", 2012 IEEE 14th International Conference on Communication Technology, 2012
[12] S. A. Cheema, K. Naskovska, M. Attar, B. Zafar and M. Haardt, "Performance Comparison of Space Time Block Codes for Different 5G Air Interface Proposals," WSA 2016; 20th International ITG Workshop on Smart Antennas, Munich, Germany, 2016, pp. 1-7.

[13] Rajesh Bhadada and Ritika Taparia. Article: Performance Analysis of Alamouti Code MIMO-OFDM Systems for Error Control and IQ Impairments. Communications on Applied Electronics 1(2):14-17, January 2015. Published by Foundation of Computer Science, New York, USA.

[14] F. Rottenberg, X. Mestre, F. Horlin and J. Louveaux, "Single-Tap Precoders and Decoders for Multiuser MIMO FBMC-OQAM Under Strong Channel Frequency Selectivity," in IEEE Transactions on Signal Processing, vol. 65, no. 3, pp. 587-600, Feb.1, 12017.

[15] Shilpa A Talele, Aarti G Ambekar and Deepshikha Hinger. Article: Improved PAPR Reduction for STBCMIMO-OFDM by using New Phase Factor with Four Transmitting. CAE Proceedings on International Conference on Communication Technology ICCT 2015(1):17-22, February 2016. Published by Foundation of Computer Science, New York, USA.

[16] R. Chandrasekhar, M. Kamaraju, M. V. S. Sairam and G. T. Rao, "PAPR reduction using combination of precoding with Mu-Law companding technique for MIMO-OFDM systems," 2015 International Conference on Communications and Signal Processing (ICCSP), Melmaruvathur, 2015, pp. 0479-0483.

[17] D. Agarwal, N. Sharan, M. P. Raja and A. Agarwal, "PAPR reduction using precoding and companding techniques for OFDM systems," 2015 International Conference on Advances in Computer Engineering and Applications, Ghaziabad, 2015, pp. 18-23.

[18] Q. Duong and H. Nguyen,"Walsh-Hadamard Precoded circular filterbank multicarrier Communications," 2017 International Conference on Recent Advances in Signal Processing, Telecommunications \& Computing (SigTelCom), Da Nang, 2017, pp. 193-198

[19] M. J. Hao and C. P. Liaw, "A Companding Technique for PAPR Reduction of OFDM Systems," 2006 International Symposium on Intelligent Signal Processing and Communications, Yonago, 2006, pp. 634-637.

[20] A. Singh, A. Jain and P. Vyavahare, "A study of peak to average power ratio for different companding techniques in VLC-OFDM system," 2016 International Conference on Advances in Computing, Communications and Informatics (ICACCI), Jaipur, 2016, pp. 2390-2393.

[21] R. Ghahremani and M. G. Shayesteh, "BER performance improvement and PAPR reduction in OFDM systems based on combined DHT and $\mu$-law companding," 2014 22nd Iranian Conference on Electrical Engineering (ICEE), Tehran, 2014, pp. 1483-1487.

[22] E. Singh, M. Arif, V. Shrivastava and R. Bhatia, "Nonlinear companding technique for PAPR reduction in OFDM," 2014 International Conference on Signal Propagation and Computer Technology (ICSPCT 2014), Ajmer, 2014, pp. 801-805. 